EXTENDED REPORT

\title{
Vitamin C and the risk of developing inflammatory polyarthritis: prospective nested case-control study
}

\author{
D J Pattison, A J Silman, N J Goodson, M Lunt, D Bunn, R Luben, A Welch, S Bingham, K-T Khaw, \\ N Day, D P M Symmons
}

Ann Rheum Dis 2004;63:843-847. doi: 10.1136/ard.2003.016097

See end of article for authors' affiliations

.....................

Correspondence to: Professor D Symmons, Arthritis Research Campaign (arc) Epidemiology Unit, University of Manchester, Oxford Road, Manchester M13 9PT, UK; deborah. symmons@man.ac.uk

Accepted 1 December 2003

\begin{abstract}
Objective: To investigate whether, there is an association between consumption of fruit and vegetables and dietary antioxidants and the risk of developing inflammatory polyarthritis (IP).

Methods: In a prospective, population based, nested case-control study of residents of Norfolk, UK, men and women aged 45-74 years were recruited, between 1993 and 1997 through general practice age-sex registers to the Norfolk arm of the European Prospective Investigation of Cancer (EPIC-Norfolk). Dietary intake was assessed at baseline using 7 day diet diaries. Seventy three participants who went on to develop IP between 1993 and 2001 and were registered by the Norfolk Arthritis Register (NOAR) were identified. Incident cases of $I P$, assessed by general practitioners, fulfilled the criteria of two or more swollen joints, persisting for a minimum of 4 weeks. Each case of IP was matched for age and sex with two controls free of IP.

Results: Lower intakes of fruit and vegetables, and vitamin $C$ were associated with an increased risk of developing IP. Those in the lowest category of vitamin C intake, compared with the highest, increased their risk of developing IP more than threefold, adjusted odds ratio (OR) with $95 \%$ confidence intervals (Cl) 3.3 $(95 \% \mathrm{Cl} 1.4$ to 7.9$)$. Weak inverse associations between vitamin $\mathrm{E}$ and $\beta$-carotene intake and IP risk were found.

Conclusion: Patients with IP (cases) consumed less fruit and vitamin $C$ than matched controls, which appeared to increase their risk of developing IP. The mechanism for this effect is uncertain. Thus similar studies are necessary to confirm these results.
\end{abstract}

$\mathrm{R}$ heumatoid arthritis (RA) is a complex disease whose aetiology is not fully understood but is almost certainly due to a combination of genetic factors and unknown environmental agents. Diet has been increasingly implicated in the pathogenesis of other chronic diseases like cardiovascular disease ${ }^{12}$ and some cancers, ${ }^{3}$ with particular interest in the possibly protective role of fruit and vegetables and their high antioxidant nutrient content. Cardiovascular disease and RA share very similar inflammatory and immunological responses, ${ }^{4}$ with increased production of reactive free oxygen radicals, and proinflammatory cytokines. ${ }^{5}$ Products of free radical oxidation have in fact been identified in the synovial fluid of inflamed rheumatoid joints, ${ }^{67}$ which supports the theory that inflammation is mediated by free radical activity. A major role of the exogenous antioxidants, vitamins $C$ and $E$ ( $\alpha$-tocopherol), $\beta$-carotene, and selenium, is to act as efficient scavengers of reactive oxygen radicals, thereby protecting against oxidative damage. Not surprisingly, the role of antioxidant micronutrients in the study of chronic, inflammatory disease has generated much interest.

Low plasma levels of antioxidants have also been found in patients with adult ${ }^{8}$ and juvenile RA $^{9}$ compared with healthy controls, although it is unclear in established disease whether this state exists before disease onset or as a result of the inflammatory process. In samples collected before the onset of symptoms, lower levels of $\alpha$-tocopherol, $\beta$-carotene, and selenium have been identified in the serum of people who subsequently developed RA compared with those who did not. ${ }^{10-12}$

Epidemiological studies in RA need to be able to distinguish factors that may be involved in the initiation of the disease as opposed to those which influence its course (that is, severity). Therefore, it is essential to collect dietary information before the onset of symptoms of inflammatory arthritis (IP). Our study aimed at investigating the association between fruit and vegetable and dietary antioxidant intake and the onset of undifferentiated IP in a population in whom diet had been measured before the onset of symptoms.

\section{METHODS}

Study design

This was a prospective, population based, nested case-control study made possible by the coincidental investigation of the same population by two independent studies: the Norfolk arm of the European Prospective Investigation of Cancer (EPIC-Norfolk) and the Norfolk Arthritis Register (NOAR). Details of both studies have been published elsewhere. ${ }^{13}{ }^{14}$ The dietary intake of all participants was assessed at baseline using a 7 day diet diary, thereby ensuring that diet was measured before the onset of symptoms in new cases of IP. Diets of cases were compared with diets of a referent group who had not developed IP.

\section{Baseline population survey in EPIC-Norfolk}

Briefly, EPIC-Norfolk is a continuing, population based, prospective study investigating dietary and other risk factors for cancer in men and women. Participants aged between 45 and 74 years at baseline were recruited from general practice age-sex registers. ${ }^{13}$ Baseline investigations included dietary assessment, a clinical examination, with height (in metres) and weight (in $\mathrm{kg}$ ) measured, and used to calculate body mass index $(\mathrm{BMI})\left(\mathrm{kg} / \mathrm{m}^{2}\right)$, and a comprehensive health and

Abbreviations: ACR, American College of Rheumatology; BMI, body mass index; EPIC-Norfolk, Norfolk arm of the European Prospective Investigation of Cancer; IP, inflammatory polyarthritis; NOAR, Norfolk Arthritis Register; RA, rheumatoid arthritis; RNI, UK Reference Nutrient Intake 
Table 1 Median (IQR) daily food and nutrient intakes between cases and controls

\begin{tabular}{llll}
\hline & $\begin{array}{l}\text { Cases } \\
(\mathbf{n}=\mathbf{7 3})\end{array}$ & $\begin{array}{l}\text { Controls } \\
(\mathbf{n}=146)\end{array}$ & p Value* \\
\hline Energy (M) & $7.4(6.1-8.8)$ & $7.7(6.4-8.9)$ & 0.28 \\
Fruit (g/day) & $100.0(44.4-229.1)$ & $132.9(75.0-216.7)$ & 0.07 \\
Vegetables (g/day) & $81.3(42.5-117.4)$ & $93.1(54.7-124.3)$ & 0.42 \\
Fruit and vegetables (g/day) & $187.4(110.0-312.5)$ & $228.7(162.5-326.2)$ & 0.09 \\
Vitamin C (mg/day) & $63.4(41.8-105.8)$ & $78.2(52.5-107.9)$ & 0.04 \\
Vitamin E (mg/day) & $6.3(4.1-8.0)$ & $6.4(4.8-8.7)$ & 0.10 \\
$\beta$-Carotene ( $\mu$ g/day) & $1753.7(1092.8-2586.9)$ & $1719.7(1216.7-2661.0)$ & 0.60 \\
Retinol ( $\mu \mathrm{g} /$ day) & $282.9(182.8-488.0)$ & $288.7(193.0-450.9)$ & 0.67 \\
Selenium ( $\mu \mathrm{g} /$ day) & $52.5(41.2-65.1)$ & $52.0(40.0-65.3)$ & 0.87 \\
\hline *Wilcoxon signed rank test. & & & \\
\hline
\end{tabular}

lifestyle questionnaire. The questionnaire provided information on medical and social histories, including a detailed smoking history from which pack-years of smoking were estimated. Each participant was assigned a Townsend score (an index of social deprivation) based on their residential postcode. ${ }^{15}$ Between 1993 and 1997, 25663 people had attended for clinical examination of whom 23654 completed a 7 day food diary. ${ }^{13}$

\section{Dietary assessment}

A trained nurse gave participants detailed instructions on how to complete the diet diary at the baseline clinic visit. Participants were asked to estimate the quantity of food and drink consumed using household measures ${ }^{16}$ and food portion photographs (printed in the diary) that illustrated small, medium, and large portions of various foods.

\section{Ascertainment of cases and controls}

Cases were participants in EPIC-Norfolk who went on to develop IP and were referred by their general practitioner (GP) to NOAR, a prospective, primary care based, inception study to identify and follow up incident cases of IP in Norfolk. Patients are referred to NOAR if they are over 16 years of age and present with a history of two or more swollen joints lasting for 4 weeks or more, with the onset of symptoms after 1 January $1990 .^{14}$ The NOAR database was run against EPIC-Norfolk records to identify IP cases already participating in EPIC at the time of their symptom onset. Two EPIC-Norfolk subjects, free of IP at baseline, acted as controls for each case. Cases and controls were matched for sex, age (to within 3 years), and date of baseline dietary assessment to within 3 months.

\section{Statistical analysis}

Data from the food diaries for all cases and controls were entered onto computer by one of us who did not know the case-control status (DJP). Data were analysed for the daily intake of the foods and nutrients of interest using a specially developed programme: DINER (Data Into Nutrients for Epidemiological Research), ${ }^{17}$ based on UK standard food composition tables. ${ }^{18}$

Dietary intake of foods and nutrients is expressed as the median and interquartile range (IQR) (table 1). We used the Wilcoxon sign rank test to compare medians between the two groups whilst maintaining the matched sets, and the $\chi^{2}$ test was used to compare the proportion of cases and controls who were smokers and obese (BMI >30). Foods and nutrients were categorised according to tertiles of intake based on the intake of the whole group. The highest tertile was used as the referent group and odds ratios (OR) and 95\% confidence intervals (CI) were estimated for the lowest and middle tertiles of intake using conditional logistic regression, again to maintain matching. We also created a dichotomous variable for vitamin $\mathrm{C}$ using the current UK Reference Nutrient Intake (RNI) of $40 \mathrm{mg} /$ day as the cut off value. ${ }^{19}$ Pack-years of smoking, Townsend deprivation score, and total energy intake were considered as potential confounding factors and entered as continuous variables into the regression model. Vitamin C was also considered as a confounder when neither it nor fruit was the variable being investigated. BMI was categorised as obese or not and entered as a categorical variable. All analysis was performed using STATA $7 .^{20}$

Ethical approval for both studies was obtained from the Norwich District Health Authority Research Ethics Committee, and all participants gave informed consent. ${ }^{13}{ }^{14}$

Table 2 Demographic and anthropometric characteristics of matched cases and controls. Values are medians (IQR) unless otherwise stated

\begin{tabular}{|c|c|c|c|}
\hline & $\begin{array}{l}\text { Cases } \\
(n=73)\end{array}$ & $\begin{array}{l}\text { Controls } \\
(n=146)\end{array}$ & p Value* \\
\hline Women, No (\%) & $51(70)$ & $102(70)$ & \\
\hline Age in years (range) & $60(52-68)$ & $61(52-68)$ & \\
\hline Height (m) & $164.4(159.6-170.5)$ & $161.8(157.8-169.5)$ & 0.03 \\
\hline Weight (kg) & $72.6(67.4-82.4)$ & $70.8(63.0-80.2)$ & 0.09 \\
\hline BMI $\left(\mathrm{kg} / \mathrm{m}^{2}\right)$ & $27.1(24.9-30.0)$ & $26.3(24.3-29.2)$ & 0.42 \\
\hline Obesity: $\mathrm{BMI}>30, \mathrm{No}(\%)$ & $18(25)$ & $27(18)$ & $0.29+$ \\
\hline \multicolumn{4}{|l|}{ Smoking, No (\%) } \\
\hline Current & $15(21)$ & 19 (13) & \\
\hline Former & $28(39)$ & $57(40)$ & $0.28 \dagger$ \\
\hline Never & $28(39)$ & $68(47)$ & \\
\hline Pack-years of smoking & $25.0(9.0-34.0)$ & $12.6(5.3-26.5)$ & 0.03 \\
\hline Townsend deprivation scoreł & $-2.61(-3.48$ to -1.11$)$ & $-2.51(-3.6$ to -1.21$)$ & 0.71 \\
\hline
\end{tabular}

*Wilcoxon signed rank test; $\uparrow \chi^{2}$ test; $\ddagger$ Townsend deprivation score: larger numbers indicate higher level of deprivation. 
Table 3 Association between tertiles of fruit, vegetables, and fruit plus vegetable intake, and IP. Lowest and middle tertiles of intake are compared with the highest tertile

\begin{tabular}{|c|c|c|c|c|c|}
\hline & $\begin{array}{l}\text { Cases } \\
\text { No (\%) }\end{array}$ & $\begin{array}{l}\text { Controls } \\
\text { No }(\%)\end{array}$ & $\begin{array}{l}\text { Crude OR } \\
(95 \% \mathrm{CI})\end{array}$ & $\begin{array}{l}\text { Adjusted OR* } \\
(95 \% \mathrm{CI})\end{array}$ & $\begin{array}{l}p \text { Value for } \\
\text { trend }\end{array}$ \\
\hline \multicolumn{6}{|l|}{ Fruit (g/day) } \\
\hline $1 \leqslant 78$ & $33(45)$ & $40(27)$ & $1.8(0.9$ to 3.6$)$ & $1.6(0.8$ to 3.3$)$ & \multirow[t]{3}{*}{0.3} \\
\hline $2,>78-176$ & $16(22)$ & $57(39)$ & $0.6(0.3$ to 1.3$)$ & $0.6(0.3$ to 1.3$)$ & \\
\hline $3,>176$ (referent) & $24(33)$ & 49 (34) & 1.0 & 1.0 & \\
\hline \multicolumn{6}{|l|}{ Vegetables (g/day) } \\
\hline $1,<64.6$ & $25(34)$ & $48(33)$ & $1.2(0.6$ to 2.5$)$ & $1.3(0.6$ to 2.7$)$ & \multirow[t]{3}{*}{0.5} \\
\hline $2,64.6-113.0$ & $26(36)$ & $47(32)$ & $1.3(0.6$ to 2.6$)$ & $1.2(0.6$ to 2.5$)$ & \\
\hline $3,>113.0$ (referent) & $22(30)$ & $51(35)$ & 1.0 & 1.0 & \\
\hline \multicolumn{6}{|c|}{ Fruit plus vegetables ( $g /$ day) } \\
\hline $1,<167$ & $33(45)$ & $40(27)$ & $2.0(1.0$ to 4.1$)$ & $1.9(1.0,4.0)$ & \multirow[t]{3}{*}{0.08} \\
\hline $2,167-275$ & $18(25)$ & 55 (38) & $0.8(0.4$ to 1.6$)$ & $0.8(0.4$ to 1.7$)$ & \\
\hline $3,>275$ (referent) & $22(30)$ & $51(35)$ & 1.0 & 1.0 & \\
\hline
\end{tabular}

$\mathrm{n}$, number; OR, odds ratio; $\mathrm{Cl}$, confidence interval.

*Adjusted for obesity, smoking (pack-years), total energy intake.

\section{RESULTS}

Up to 31 December 2001, 74 incident cases of IP, who had participated in EPIC-Norfolk and completed the 7 day diet diary, were identified from the NOAR database. One case was subsequently found not to meet the entry criteria for NOAR and was not included in the final analysis. At the NOAR baseline assessment, 29 (40\%) cases satisfied the American College of Rheumatology (ACR) criteria for RA, ${ }^{21}$ and 27 of the 69 with available sera $(39 \%)$ were rheumatoid factor positive. Experience shows that by 5 years approximately $66 \%$ satisfy these criteria. ${ }^{22}$ This group has not yet completed 5 years of follow up, but by 2 years' follow up $60 \%$ had satisfied the ACR criteria cumulatively. The median duration between dietary assessment and symptom onset was 2.1 years (IQR 0.9- 2.9).

Table 2 shows the distribution of demographic and anthropometric characteristics presented according to case or control status. With the exception of height and smoking history, there were few important differences in baseline characteristics between cases and controls. However, sexspecific differences in height were not significant (median (IQR) height of male cases $174.0(170.8-177.4) v$ controls 173.2 (167.5-177.4), Wilcoxon test $\mathrm{p}=0.3$; and female cases 161.4 (157.8-164.9) $v$ controls 160.5 (155.9-164.5), Wilcoxon test $p=0.058)$, and cases were more likely to be obese than controls. A higher proportion of cases had "ever smoked" (61\% v 53\%, respectively; OR 1.3 (95\% CI 0.7 to 2.5$)$ ) and were heavier smokers than controls. There was no significant departure from linearity in the association between smoking and IP $(p=0.3)$. As smoking is associated with a lower consumption of fruit and vegetables ${ }^{23}$ and with an increased risk of RA, and obesity has previously been shown to be a risk factor for RA in a different group of NOAR cases and matched controls, ${ }^{24}$ pack-years of smoking and obesity were treated as potential confounding covariates and entered into the analysis.

\section{Fruit and vegetables}

Cases reported a lower, but not statistically significant, median daily fruit and vegetable consumption than controls (table 1). We investigated tertiles of fruit and vegetable intake individually and as a composite variable of fruit plus vegetables for an association with IP. Lower intakes of fruit and the composite variable were associated with an increased risk of IP, but less so for vegetables alone (table 3 ).

\section{Antioxidant nutrients}

There was a significant difference in the dietary intake of vitamin $\mathrm{C}$ between cases and controls but not for other antioxidants (table 1). Table 4 shows the crude and adjusted ORs of IP risk, based on tertiles of dietary vitamin C intake. Subjects in the lowest tertile of daily vitamin $\mathrm{C}$ intake had a more than threefold chance of being a case than those in the referent tertile, after adjusting for smoking, obesity, and total energy intake. Twenty one per cent of cases and 7\% of controls reported daily dietary vitamin $\mathrm{C}$ intakes below the UK RNI of $40 \mathrm{mg} /$ day. ${ }^{19}$ For those with an intake of vitamin C below $40 \mathrm{mg} /$ day the risk of developing IP was nearly four times greater than for those with intakes above $40 \mathrm{mg} /$ day (table 4).

Of the other antioxidants, lower intakes of vitamin $\mathrm{E}$ and $\beta$-carotene were weakly associated with an increased risk of IP (table 5), but there was no association with retinol or selenium.

Table 4 Association between dietary vitamin C (tertiles and UK RN $1^{19}$ ) and IP. Lowest and middle tertiles of intake are compared with the highest tertile

\begin{tabular}{|c|c|c|c|c|c|}
\hline & $\begin{array}{l}\text { Cases } \\
\text { No (\%) }\end{array}$ & $\begin{array}{l}\text { Controls } \\
\text { No }(\%)\end{array}$ & $\begin{array}{l}\text { Crude OR } \\
(95 \% \mathrm{Cl})\end{array}$ & $\begin{array}{l}\text { Adjusted OR* } \\
(95 \% \mathrm{Cl})\end{array}$ & $\begin{array}{l}\mathrm{p} \text { Value for } \\
\text { trend }\end{array}$ \\
\hline \multicolumn{6}{|l|}{ Tertiles of vitamin $C$ (mg/day) } \\
\hline $1,<55.7$ & $33(45)$ & 40 (27) & $2.6(1.2$ to 5.8$)$ & $3.3(1.4$ to 7.9$)$ & 0.01 \\
\hline $2,55.7-94.9$ & $19(26)$ & $54(37)$ & $0.9(0.4$ to 1.8$)$ & $0.8(0.4$ to 1.7$)$ & \\
\hline $3,>94.9$ (referent) & $21(29)$ & $52(36)$ & 1.0 & 1.0 & \\
\hline \multicolumn{6}{|l|}{ Vitamin C (mg) by RNI } \\
\hline$<40 \mathrm{mg} v \geqslant 40 \mathrm{mg}$ & $15(21) \dagger$ & $10(7) \dagger$ & $3.4(1.4$ to 8.2$)$ & 3.9 (1.5 to 9.7$)$ & \\
\hline
\end{tabular}

$\mathrm{n}$, number; $\mathrm{OR}$, odds ratio; $\mathrm{Cl}$, confidence interval.

*Adjusted for obesity, smoking and total energy intake; tcases and controls with vitamin $\mathrm{C}$ intake $<40 \mathrm{mg} /$ day 


\begin{tabular}{|c|c|c|c|c|c|}
\hline & $\begin{array}{l}\text { Cases } \\
\text { No (\%) }\end{array}$ & $\begin{array}{l}\text { Controls } \\
\text { No }(\%)\end{array}$ & $\begin{array}{l}\text { Crude OR } \\
(95 \% \mathrm{Cl})\end{array}$ & $\begin{array}{l}\text { Adjusted OR* } \\
(95 \% \mathrm{CI})\end{array}$ & $\begin{array}{l}p \text { Value for } \\
\text { trend }\end{array}$ \\
\hline \multicolumn{6}{|l|}{ Vitamin $E(m g)$} \\
\hline $1,<5.3$ & $26(36)$ & $47(32)$ & $1.6(0.7$ to 3.3$)$ & $1.3(0.6$ to 3.2$)$ & \multirow[t]{3}{*}{0.5} \\
\hline $2,5.3-7.7$ & 27 (37) & $46(32)$ & $1.6(0.8$ to 3.3$)$ & $1.6(0.7$ to 3.4$)$ & \\
\hline $3,>7.7$ (referent) & $20(27)$ & $53(36)$ & 1.0 & 1.0 & \\
\hline \multicolumn{6}{|l|}{$\beta$-carotene $(\mu \mathrm{g})$} \\
\hline $1,<1305$ & 27 (37) & $46(32)$ & $1.4(0.7$ to 2.8$)$ & $1.3(0.6$ to 2.7$)$ & \multirow[t]{3}{*}{0.6} \\
\hline $2,1305-2340$ & $24(33)$ & $49(33)$ & $1.1(0.6$ to 2.3$)$ & $1.0(0.5$ to 2.1$)$ & \\
\hline $3,>2340$ (referent) & $22(30)$ & $51(35)$ & 1.0 & 1.0 & \\
\hline \multicolumn{6}{|l|}{ Retinol $(\mu \mathrm{g})$} \\
\hline $1,<216$ & $28(38)$ & $45(31)$ & $1.2(0.6$ to 2.2$)$ & 1.1 (0.5 to 2.3$)$ & \multirow[t]{3}{*}{0.6} \\
\hline $2,216-385$ & $20(28)$ & $53(36)$ & $0.7(0.3$ to 1.4$)$ & $0.7(0.3$ to 1.6$)$ & \\
\hline $3,>385$ (referent) & 25 (34) & $48(33)$ & 1.0 & 1.0 & \\
\hline \multicolumn{6}{|l|}{ Selenium ( $\mu \mathrm{g})$} \\
\hline $1,<45.8$ & $24(33)$ & 49 (33.5) & $1.0(0.5$ to 2.0$)$ & $0.9(0.4$ to 1.9$)$ & \multirow[t]{3}{*}{0.8} \\
\hline $2,45.8-60$ & 25 (34) & 48 (33) & $1.1(0.5$ to 2.1$)$ & $1.0(0.5$ to 2.1$)$ & \\
\hline $3,>60$ (referent) & $24(33)$ & 49 (33.5) & 1.0 & 1.0 & \\
\hline
\end{tabular}

\section{DISCUSSION}

Fruit and vegetable consumption and, in particular, dietary vitamin C may have an important role in the development of IP. Although a lower intake of fruit and vegetables was associated with a doubling in the risk of developing IP, vitamin $\mathrm{C}$ alone demonstrated the strongest association. People who consumed less than $56 \mathrm{mg}$ of vitamin $\mathrm{C}$ daily (above the current UK RNI of $40 \mathrm{mg} /$ day) had a more than threefold increase in the risk of IP compared with those who consumed more.

\section{Strengths}

This was a prospective, population based study with dietary and clinical assessments undertaken before the onset of IP. Incident cases of IP were easily identified from the NOAR database, and all fulfilled the same entry criteria. Height and weight were measured at the baseline EPIC clinical examination by a standard procedure, thus providing an accurate assessment of BMI rather than self reported values. A detailed smoking history was also obtained and the effects of smoking controlled for in our subsequent analyses. Diet diaries were completed on the day that food was consumed, reducing the likelihood of recall bias, and furthermore, as records were completed before the onset of IP, eating behaviour would not have been influenced by the presence of disease. Although we are not aware of any other publications of associations between dietary vitamin $\mathrm{C}$ and the risk of inflammatory arthritis, higher intakes of cooked vegetables, ${ }^{25}$ cruciferous vegetables, and fruit ${ }^{26}$ have been reported to protect against the onset of RA in two studies of very different designs, which used food frequency questionnaires to assess diet rather than diet diaries. The 7 day "estimated" food record method of dietary assessment has previously been validated against weighed food records, 24 hour urine collections, and serum biomarkers ${ }^{27}$ and when compared with other methods, including food frequency questionnaires, found to have greater accuracy in assessing individual dietary intake.

\section{Limitations}

This was a relatively small study, but we matched two controls with each case in order to increase the statistical power to detect significant differences in dietary intake between cases and controls. The cases and controls came from a large population based sample and the number of new cases of IP that we identified is representative of the known incidence of IP. ${ }^{22}$ EPIC-Norfolk participants have been shown to be similar to UK population samples with respect to anthropometry but contain a lower proportion of smokers. ${ }^{13}$ Therefore, the generalisability of our results may be limited. These data do not include vitamin $\mathrm{C}$ intake from dietary supplements, but from the information we have examined so far, supplements likely to contain vitamin $\mathrm{C}$ were used by $14 \%$ of controls compared with $6 \%$ of cases, which supports the association we observed with dietary vitamin C.

\section{Implications}

Our findings are biologically plausible, given the antioxidant activity of vitamin C, although it was surprising that only weak associations were found between the other antioxidants and IP risk. However, fruit and vegetables contain many important antioxidant micronutrients, like carotenoids, for which vitamin $\mathrm{C}$ may be acting as a marker. Possibly then, a low dietary intake of fruit and vegetables and vitamin $\mathrm{C}$ may be increasing the risk of developing IP through a deficiency in powerful antioxidant micronutrients not accounted for in our analyses. A poor diet is also associated with other harmful behaviour, such as smoking, ${ }^{23}$ a known risk factor for RA. We have taken smoking into account in the analyses so it is unlikely that this is responsible for our findings.

In conclusion, this study found that a low intake of fruit and, particularly dietary vitamin $\mathrm{C}$, is associated with an increased risk of developing IP. These results may have implications for the primary prevention of inflammatory polyarthritis.

\section{Authors' affiliations}

D J Pattison, A J Silman, N J Goodson, M Lunt, D P M Symmons,

Arthritis Research Campaign (arc) Epidemiology Unit, University of Manchester, Oxford Road, Manchester M13 9PT, UK

D Bunn, Norfolk Arthritis Register, Norfolk \& Norwich University Hospital, Colney Lane, Norwich NR4 7UZ, UK

R Luben, A Welch, K-T Khaw, N Day, Department of Public Health and Primary Care, Institute of Public Health, University of Cambridge School of Clinical Medicine, Cambridge, UK

S Bingham, MRC Dunn Human Nutrition Unit, Welcome Trust/MRC Building, Hills Road, Cambridge CB2 2XY, UK 


\section{REFERENCES}

1 Ness AR, Powles JW. Fruit and vegetables, and cardiovascular disease: a review. Int J Epidemiol 1997;26:1-13.

2 Khaw KT, Bingham S, Welch A, Luben R, Wareham N, Oakes S, et al. Relation between plasma ascorbic acid and mortality in men and women in EPIC-Norfolk prospective study: a prospective population study. Lancet 2001;357:657-63.

3 Block C. Epidemiologic evidence regarding vitamin C and cancer. Am J Clin Nutr 1991;54:1310-14S.

4 Pasceri V, Yeh ETH. A tale of two diseases: atherosclerosis and rheumatoid arthritis. Circulation 1999:100:2124-6.

5 Halliwell B, Gutteridge JMC. Free radicals, other reactive species and disease. In: Free radicals in biology and medicine. Oxford: Oxford, 1999:617-783.

6 Merry P, Winyard PG, Morris CJ, Grootveld M, Blake DR. Oxygen free radicals, inflammation, and synovitis: the current status. Ann Rheum Dis 1989:48:864-70.

7 Lunec J, Halloran SP, White AC, Dormandy TL. Free-radical oxidation (peroxidation) products in serum and synovial fluid in rheumatoid arthritis. J Rheumatol 1981;8:233-45.

8 Kiziltunç A, Cogalgil S, Cerrahoglu L. Carnitine and antioxidants levels in patients with rheumatoid arthritis. Scand J Rheumatol 1998;27:441-5.

9 Helgeland $M$, Svendsen E, Førre $\varnothing$, Haughen M. Dietary intake and serum concentrations of antioxidants in children with juvenile arthritis. Clin Exp Rheumatol 2000; 18:637-41

10 Helï̈vaara M, Knekt $P$, Aho K, Aaran R-K, Alfthan G, Aromaa A. Serum antioxidants and risk of rheumatoid arthritis. Ann Rheum Dis 1994;53:51-3.

11 Comstock GW, Burke AE, Hoffman SC, Helzlsouer KJ, Bendich A, Masi A, et al. Serum concentrations of $\alpha$ tocopherol, $\beta$ carotene, and retinol preceding the diagnosis of rheumatoid arthritis and systemic lupus erythematosus. Ann Rheum Dis 1997:56:323-5.

12 Knekł P, Heliövaara M, Aho K, Alffhan G, Marniemi J, Aromaa A. Serum selenium, serum alpha-tocopherol, and the risk of rheumatoid arthritis. Epidemiology 2000;1 1:402-5.

13 Day NE, Oakes S, Luben R, Khaw K-T, Bingham SA, Welch A, et al. EPICNorfolk: study design and characteristics of the cohort. Br J Cancer 1999;80(suppl 1):95-103.

14 Symmons DPM, Barrett EM, Bankhead CR, Scott DGI, Silman AJ. The incidence of rheumatoid arthritis in the United Kingdom: results from the Norfolk Arthritis Register. Br J Rheumatol 1994;33:735-9.
15 Townsend $\mathbf{P}$, Phillimore $\mathrm{P}$, Beattie A. Health and deprivation in the north. London: Croon Helm, 1988.

16 Bingham SA, Welch AA, McTaggart A, Mulligan AA, Runswick SA, Luben R. Nutritional methods in the European prospective investigation of cancer in Norfolk. Public Health Nutr 2001;4:847-58.

17 Welch AA, McTaggart A, Mulligan AA, Luben R, Walker N, Khaw K-T, et al. DINER (Data Into Nutrients for Epidemiological Research) a new data entry program for nutritional analysis in the EPIC-Norfolk cohort. Public Health Nutr 2001;4:1253-65.

18 McCance, Widdowson's. The composition of foods. Cambridge: Royal Society of Chemistry and MAFF, 1991.

19 HMSO. Dietary reference values for food energy and nutrients for the United Kingdom: Report on health and social subjects 41. London: HMSO, 1991.

20 StataCorp. Stata statistical software. College Station, Texas: Stata Corporation, 2001.

21 Arnett FC, Edworthy SM, Bloch DA, McShane DJ, Fries JF, Cooper NS, et al. The American Rheumatism Association 1987 revised criteria for the classification of rheumatoid arthritis. Arthritis Rheum 1988;31:315-24.

22 Wiles N, Symmons DPM, Harrison B, Barrett E, Barrett JH, Scott DGl, et al. Estimating the incidence of rheumatoid arthritis. Arthritis Rheum 1999:42:1339-46.

23 Serdula MK, Byers T, Mokdad AH, Simoes E, Mendlein JM, Coates RJ. The association between fruit and vegetable intake and chronic disease risk factors. Epidemiology 1995;7:161-5.

24 Symmons DPM, Bankhead CR, Harrison BJ, Brennan P, Barrett EM, Scott DGI, et al. Blood transfusion, smoking and obesity as risk factors for the development of rheumatoid arthritis. Results from a primary care-based incident case-control study in Norfolk, England. Arthritis Rheum 1997;40:1955-61.

25 Linos A, Kaklamani VG, Kaklamani E, Koumantaki Y, Giziaki E, Papazoglou $S$, et al. Dietary factors in relation to rheumatoid arthritis: a role for olive oil and cooked vegetables? Am J Clin Nutr 1999;70:1077-82.

26 Cerhan JR, Saag KG, Merlino LA, Mikuls TR, Criswell LA. Antioxidant micronutrients and risk of rheumatoid arthritis in a cohort of older women. Am J Epidemiol 2003;157:345-54.

27 Bingham SA, Cassidy A, Cole TJ, Welch A, Runswick SA, Black AE, et al. Validation of weighed records and other methods of dietary assessment using the 24 hour urine nitrogen technique and other markers. Br J Nutr 1995; 73:531-50. 